\title{
The Uruguay Round and Welfare in Some Distorted Agricultural
}

\section{Economies}

\author{
James E. Anderson \\ Boston College and NBER
}

$1 / 30 / 97$

\begin{abstract}
There is widespread concern about the effect of the Uruguay Round policy changes on world agricultural prices and consequently upon the welfare of developing countries. Assessing welfare changes with the standard terms of trade effect calculation can be misleading for distorted economies, since the distortion effect operates in addition or in opposition to the terms of trade effect. This study reveals distortion effects which are many times larger than terms of trade effects in a study of the Uruguay Round's impact on 9 agricultural economies. In 3 of 9 cases, the distortion effect reverses the impact of the terms of trade effect. In 2 other cases the distortion effect raises a trivial terms of trade effect up to around 1\% of national income.

JEL Classification: F13, F14, O13, O20
\end{abstract}

This research was supported by the World Bank, but the usual disclaimer applies. Will Martin's help and the able research assistance of Can Erbil are gratefully acknowledged. Errors and omissions are solely the author's responsibility. 
The Uruguay Round agreements will reduce agricultural price distortions among major supplying nations. The resulting world price changes are predicted to include increases in basic food prices mixed with price decreases for some important exports such as coffee and cotton (Goldin and van der Mensbrugghe, 1995). There is widespread concern about the effect of these world agricultural price changes upon the welfare of developing countries. It appears that raising food prices paid by food importers must be bad for them. The fall in coffee and cotton prices raises a complementary concern as it appears that exporters of these products in developing countries must be hurt.

According to the standard terms of trade effect assessment of welfare changes, each $1 \%$ rise in import (export) price adds to the compensation required to maintain real income constant at a rate equal to the import (export) share of base expenditure (income). For example, a 10\% rise in the price of an import taking up 10\% of national expenditure will cause a compensation requirement equal to $1 \%$ of national income. If this is not met, there is a $1 \%$ fall in real income. Based on this reasoning and 'back of the envelope' calculations, most analysts have concluded that the welfare effects of the forecast price changes will be quite small (e.g., Goldin and van der Mensbrugghe, 1995), even for developing countries.

Assessing welfare changes with the standard terms of trade effect calculation can be misleading for distorted economies, as is well known in theory. See Tyers and Falvey (1989) and Alston and Martin (1995) for theoretical analysis of the effect of terms of trade changes when exports are subsidized. Related to this is the theory of the second-best point that liberalizations of some distortions need not be welfare-increasing due to the 
presence of cross effects with other distortions. This qualification has been shown to have practical bite, as simulation results by Loo and Tower (1990) demonstrate that the benefit of agricultural trade liberalization in the presence of domestic distortions can be substantially offset by cross effects. ${ }^{1}$ See also Clarete and Whalley (1988) for a similar exercise with Philippine data.

The theoretical qualification is practically important since agricultural exporting countries often have distorted prices in favor of producers, and a fall in agricultural prices can decrease an activity which is too large (its marginal social benefit is below its marginal social cost). Similarly, many food importers have distorted prices in favor of consumers, so that imports are in effect subsidized. In this situation, a rise in food prices causes a reduction of an activity (food importing) which is too large (its marginal social cost is above the willingness-to-pay of consumers). This distortion effect operates in addition or in opposition (as in the examples) to the terms of trade effect of the standard analysis. If in opposition, the offset can in principle be large enough to make the rise in agricultural prices actually desirable for importers, and actually undesirable for exporters. If in addition, the distortion effect can make a small terms of trade effect a big effect in total.

The closest antecedent to this paper is Anderson and Tyers (1993). They employ a partial equilibrium model (of 7 food markets for 30 agricultural trading countries) to simulate trade liberalization in a dynamic stochastic setting. Using international price comparisons, they construct domestic distortions of producer prices. In their base simulation, developing countries

\footnotetext{
${ }^{1}$ They model a 'representative' developing country with a single agricultural product and a somewhat more elaborate production structure. The benefits of an agricultural export tax cut depend on the details of assumed import tariff levels, quota rent-seeking and of excise taxation, due to the cross effect of the export tax distortion with the other distortions.
} 
lose from the trade liberalization of developed countries, as in the standard story. In their alternative simulation, they parametrically adjust downward the domestic distortion wedge for a subset of the developing countries. ${ }^{2}$ With this adjustment, trade liberalization is welfare improving for some of these countries. In contrast to Anderson and Tyers, this paper applies general equilibrium methods to a more detailed set of commodities and a more detailed set of domestic distortions and trade distortions.

The results show the practical significance of distortion effects in an analysis of the Uruguay Round's impact on a group of 9 agricultural developing nations. The distortion effects are generally much larger than the terms of trade effects, sometimes with the same sign and sometimes with opposite sign. In several cases the distortion effect is large enough to push the money metric welfare effect up from a trivial fraction to nearly one percent of national income. Dramatically, in 3 of the 9 cases the distortion effect offsets the terms of trade effect by enough to reverse the direction of welfare impacts. Overall, the correlation of the money metric welfare effects and the standard terms of trade effects across the 9 countries is equal to .63 .

The calculations analyze the welfare effect of external agricultural price changes for 15 commodities in 9 agricultural trading countries with a variety of distortions of trade and of domestic production and consumption through subsidy and tax policies. The countries are chosen on the basis of availability of detailed trade distortions data and of detailed agricultural production and distortion data. All these countries are net exporters of agricultural products though some of them are importers of key foods. The commodities are chosen

\footnotetext{
${ }^{2}$ The discount on the distortion wedge is $15 \%$ for one group and $30 \%$ for another group of developing countries. The adjustments are based on Krueger et al. (1988), who calculate a net disincentive to agriculture of policies which protect nonagricultural activities for a set of developing countries.
} 
to fit the structure of the RUNS model (Goldin and van der Mensbrugghe, 1995), which is the source of the forecast price changes for the 15 commodities. Sensitivity analysis is conducted with other price change estimates.

The impact of simultaneous removal of domestic agricultural distortions and the external price changes is also calculated for the subset of countries for which the domestic distortions data is available. This simulation combined with the first again reveals that distortion effects arising through domestic distortions can be larger than terms of trade effects.

The welfare measurement is done using a very simple Computable General Equilibrium (CGE) model designed to focus on the details of terms of trade changes and trade distortions while suppressing much detail of the production structure. The suppression is for convenience, to allow analysis where detailed production structure information is missing. Related work with this type of CGE model (see Anderson and Neary, 1994, for a summary) shows that the details of the trade and domestic distortion structure are very important to the type of inference which may be drawn.

Sensitivity analysis reveals that all qualitative conclusions are robust to variations in assumed values of world price changes, to possible errors in domestic distortion measures and to elasticity values. However, the numerical results for individual countries are sensitive to domestic distortion levels and to some extent to variations in assumed world price changes.

The results depend more fundamentally on aspects of model structure which are difficult to probe for sensitivity. Besides the limitations of the simple production structure of the model, the analysis is conducted with a representative consumer/producer. This assumption ignores the distributional concerns which motivate much agricultural policy in all 
countries. As usual, the welfare results may be taken as indicating a potential surplus which could in principle be used to achieve distributional goals.

The results taken together emphasize that reliable conclusions about the welfare effects of world agricultural price changes must be based on general equilibrium models incorporating the effects of both trade distortions and domestic agricultural distortions. Due to data limitations, only a small group of countries is analyzed. In future work, effort should be devoted to developing the detailed trade distortions and domestic distortions data necessary to apply the method used here to other poor net agricultural importing countries.

Section I reviews the basic theory of terms of trade changes and welfare. Section II is a technical description of the computable general equilibrium model used to simulate the welfare changes due to world price changes. Section III presents the results.

\section{Agricultural Price Changes and Welfare}

Changes in agricultural prices affect welfare through the usual terms of trade effect and through several channels of distortions. In subsection A, the welfare effect of world price changes on a small country with tariffs is analyzed. In subsection $\mathrm{B}$, the analysis is extended to allow for domestic distortions and for quotas.

\subsection{World Price Changes and Welfare with Tariffs}

It is well known from the theory of the second best that in the presence of distortions, perverse results are possible. Actual demonstrations of perverse results are, however, rather rare. External rises in the price of imported food when imports (consumption) is subsidized provide an interesting example. 
To see the technical essentials, suppose that a vector of traded goods are purchased or sold at external price vector $\mathrm{p}^{*}$ and trade domestically at a price vector $\mathrm{p}$, the difference $\mathrm{p}-\mathrm{p}^{*}$ being equal to a specific tax/subsidy vector. The balance of trade function for the representative agent economy is equal to

$$
b\left(p, p^{*}, u\right)=e(p, u)-\left(p-p^{*}\right)^{\prime} e_{p}(p, u) .
$$

Here, $\mathrm{e}$ is the trade expenditure function and $\mathrm{e}_{\mathrm{p}}$ is the trade vector, by Shephard's Lemma. It is also convenient to denote the trade vector as $\mathrm{m}$, with positive elements of $\mathrm{m}$ for imports and negative elements of $\mathrm{m}$ for exports. Here and below, a subscript denotes differentiation, save when index variables $\mathrm{i}, \mathrm{j}$ or $\mathrm{s}$ are used. Given $\mathrm{p}^{*}$ and a fixed policy $\mathrm{p}-\mathrm{p}^{*}$, the equilibrium level of utility $u$ is determined by the balanced trade requirement $b()=$.0 .

Now consider the effect of a rise in the external price vector of traded goods $\mathrm{p}^{*}$. The policy vector $\mathrm{p}-\mathrm{p}^{*}$ is assumed to be unchanged, so the rise in $\mathrm{p}^{*}$ passes fully through to $\mathrm{p}$ and the vector of changes in foreign exchange required to support $\mathrm{u}$ with the new price vector $\mathrm{p}^{*}$ is equal to

$$
b_{p^{*}}^{\prime}=m^{\prime}-\left(p-p^{*}\right)^{\prime} m_{p} .
$$

Using the symmetry of cross effects, the ith element of the row vector $b_{p^{*}}^{\prime}$ is equal to

$$
b_{i} \quad=m_{i}-\left(p-p^{*}\right)^{\prime} \partial m_{i} / \partial p .
$$

Based on this formula, a local approximation to the welfare change of a set of price changes expressed as a proportion of national income y is:

$$
\sum_{i} \frac{1}{y} b_{i} \hat{p}_{i}=\sum_{i} \frac{m_{i} p_{i}}{y} \hat{p}_{i}+\sum_{i, j} \tau_{j} \frac{p_{j} m_{j}}{y}\left\{\varepsilon_{j i}\right\} \hat{p}_{i}
$$

where $\tau_{\mathrm{j}}$ denotes the ad valorem tax on good $\mathrm{j},\left(\mathrm{p}_{\mathrm{j}}-\mathrm{p}_{\mathrm{j}}^{*}\right) / \mathrm{p}_{\mathrm{j}}$ and $\varepsilon_{j i}$ denotes the elasticity of compensated import demand $j$ with respect to price $i$. The equation says that the percentage change in real income due to the external 
price changes is equal to the terms of trade effect, the first term, plus the distortion effect, the second term. The terms of trade effect is equal to the sum of the trade shares times the percentage changes in external prices. It is readily calculated. The second term is the familiar dead weight loss term when the $\hat{p}^{\prime}$ s are due to tax changes.

More intuition can be drawn out by focusing on a special case. For the Constant Elasticity of Substitution (CES) import demand system (identified with CES final demand and Ricardian production for example) the elasticity $\varepsilon_{i j}$ is equal to $\sigma\left(-\delta_{\mathrm{ij}}+\mathrm{s}_{\mathrm{j}}\right)$, where $\sigma$ is the elasticity of substitution, $\delta_{\mathrm{ij}}$ is the Kronecker delta and $s_{j}$ is the expenditure share of good $j$. The marginal welfare cost of a rise in external price $i$ in the CES setup reduces to

$$
m_{i}\left[1+\sigma \tau_{i}-\sigma \Sigma \tau_{j} s_{j}\right] .
$$

If good $\mathrm{i}$ is subsidized while trade on average is taxed $\left(\Sigma \tau_{\mathrm{j}} \mathrm{S}_{\mathrm{j}}\right.$ is positive), the square bracket term is less than one, the cost of a rise in the external price is lower than in the absence of distortions. If $\tau_{\mathrm{i}}$ is large in absolute value relative to 'average' taxes, or if $\sigma$ is large, a rise in external food prices has a negative welfare cost; i.e., it is welfare improving. Plausible parameter values can produce the 'perverse' result. ( $\tau_{\mathrm{i}}$ is equal to $\left(\mathrm{p}_{\mathrm{i}}-\mathrm{p}^{*} \mathrm{i}\right) / \mathrm{p}_{\mathrm{i}}$. A $40 \%$ subsidy defined by $\mathrm{p}=0.6 \mathrm{p}^{*}$ implies a value of $\tau_{\mathrm{i}}$ equal to 0.67 , and an elasticity in excess of 1.5 suffices for the 'perverse' result, even if the 'average' tax is equal to zero.)

This marginal analysis is informative in showing possibilities. It is also instructive because it shows that the perversity is due to the inefficient given policy. However, it can be misleading because most general equilibrium production structures with imported inputs necessarily have some complementarity in their excess demand systems (Lopez and Panagariya, 1992) rather than the universal substitutability of the example. The CGE 
model used in this paper exhibits complementarity between exports and imported inputs.

\subsection{Domestic Distortions and Quotas}

More realistic complications of general equilibrium complicate the analysis in an interesting and practically important way. First, agriculture has significant consumption and production distortions in addition to trade distortions. See Anderson, Bannister and Neary (1995) for a discussion of related issues. Subsidized consumption acts in part like subsidized imports (or taxed exports) while subsidized production acts in part like taxed imports (or subsidized exports). Second, the presence of quotas leads to cross effects in which changes in external prices have effects on the amount of rent lost to foreigners. These can lead to 'perverse' results.

As for nontraded nonagricultural goods distortions, while undoubtedly important, they are omitted from the model.

\section{Description of the Model}

The model is fully Walrasian: all nontraded goods (and all quotaconstrained) markets clear with flexible prices. The closure rule is that net external borrowing must be no more than in the base year of the model. This is appropriate for a medium term model of a credit constrained economy, but it obviously ignores potentially important intertemporal linkages. (Investment expenditure is subsumed into 'expenditure', which shuts down potentially powerful linkages from policy changes to investment plans to changes in levels of distorted activities.)

The simple CGE model used in this study has a CES/CET production structure and a CES final demand structure. Imported inputs and a single nonproduced and nontraded domestic input are used to produce domestic 
'activity'. Domestic activity is jointly allocated to a composite nontraded good and agricultural production. The agricultural production is in turn divided into a set of home (nontraded) agricultural goods and exports. The elasticity of transformation between home and exported agricultural goods is thus allowed to be higher than that between agricultural goods and nonagricultural goods. The nontraded goods (composite and agricultural) are produced and consumed domestically. For the purpose of this study, all agricultural imports are treated as final goods. On the demand side, CES preferences determine expenditure between an agricultural aggregate, the nontraded composite good, and other final imports. Within agriculture, a CES aggregator divides expenditure among the home and imported agricultural goods. Thus, the elasticity of substitution in consumption between domestic and imported food can be greater than the elasticity of substitution between food and any other type of good. The chief limitation of this nested CES/CET setup is that agricultural production and nonagricultural production are assumed to have identical joint production technologies.

See Anderson and Neary (1996) for a summary and discussion of a version of the CES/CET model which does not break out agricultural production. A more detailed description of the CES/CET model is in Anderson (1995). In contrast to the simple CGE model used there, the present study will disaggregate exports and nontraded goods to allow detailed focus on the effect of Uruguay Round reforms on the export side of the economy and on domestic agricultural distortions. Since exports and domestic 
agricultural production may be distorted, the model is expanded to incorporate the effect of export distortions.

A flow chart provides a good introduction to the essential linkages of the a simplified form of the model.

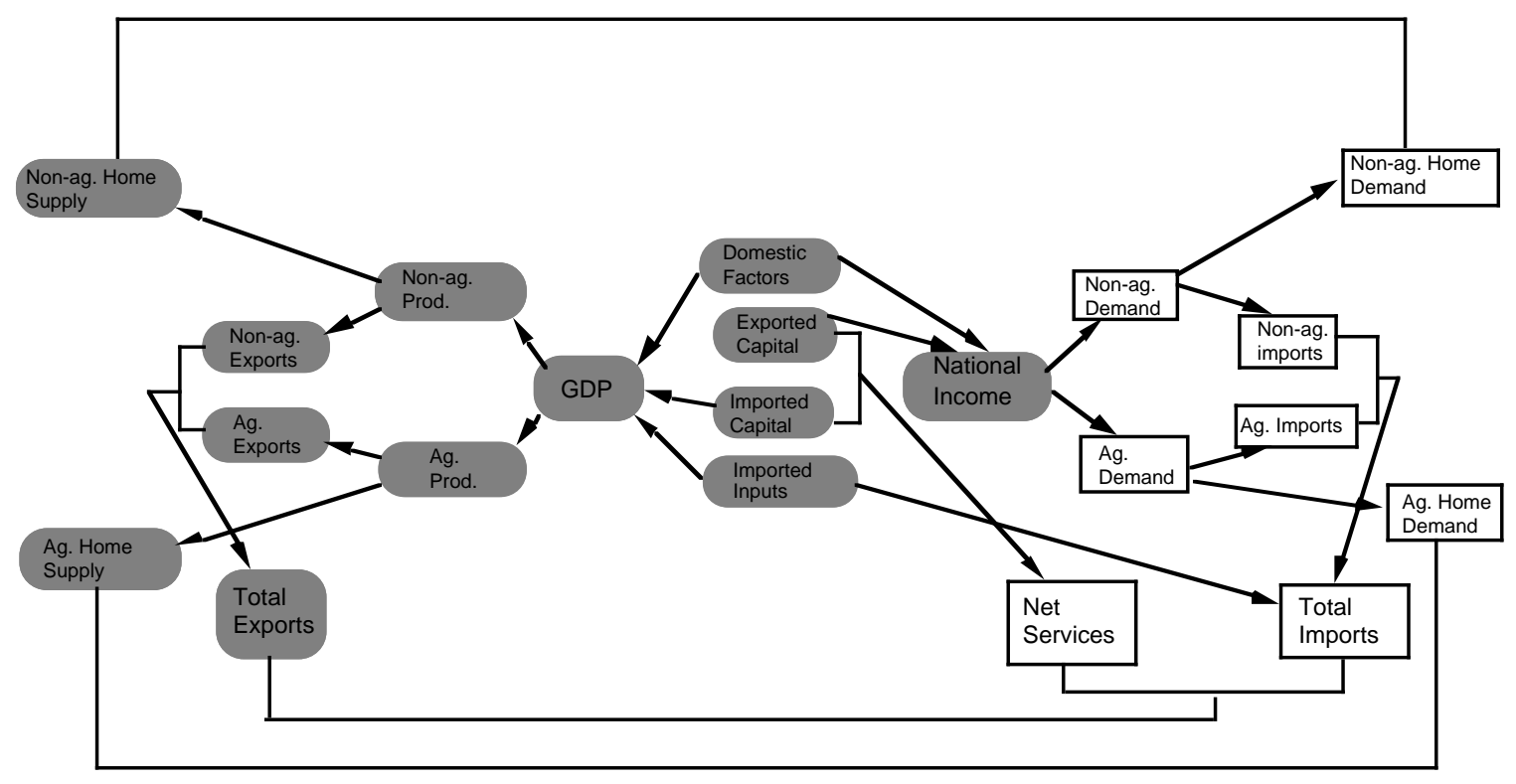

The outside lines portray the nontraded goods market clearance conditions (on the top and bottom) and the balance of payments constraint (on the bottom). Together the market clearance equations and the balance of payments constraint determine the prices of the nontraded goods and the level of real income. The interior arrows portray the linkage from factor supplies to Gross Domestic Product and to National Income and from there to supply and demand. The aggregate production function puts the factors together in GDP, moving to the left from the factor supplies column in the middle of the chart. The aggregate GDP is split into component products by the arrows moving to the left from GDP. The factor supplies yield National 
Income, moving to the right from the factor supplies column. National income equals expenditure, which is split into expenditure components by the arrows moving to the right. The economy potentially has both foreign owned factors helping make domestic product ("Imported Capital") and domestically owned factors earning income abroad ("Exported Capital"). These primary factors need not be 'capital', of course. In practice, the data only permits identifying Net Services trade, the balance of the two. While the direction of the arrows is helpful in thinking through the structure of the economy, there is of course simultaneous determination of all magnitudes as the endogenous home goods prices and the level of real income adjust to satisfy the market clearance and balance of payments equilibrium conditions.

The CGE model assumes that primary and intermediate inputs are combined to make GDP with a CES production function, acting along the arrows to the left of GDP. The GDP is distributed across outputs with a twolevel CET joint output function; the upper level for the split between agricultural and non-agricultural production and the lower level for the split between exports and home goods. This is reflected in the hierarchy of arrows to the left of GDP. National income is allocated across final demand with a two level CES expenditure function. The upper level is for the allocation between non-agricultural imports, non-agricultural home goods, and agricultural goods. The lower level is for allocation between imported and domestic agricultural goods. This is reflected in the hierarchy of arrows to the right of National Income.

External price changes in agriculture affect the flow chart model by altering the forces represented in (1) the arrow from agricultural expenditure 
to agricultural imports, and (2) the arrow from agricultural production to agricultural exports. This will of course result in new level of endogenous prices and real income.

The actual CGE model is more complex than the flow chart in three theoretically and practically important ways. First, agricultural production, trade and consumption are broken down into the 15 sectors of the RUNS model. The agricultural aggregates are assumed to have greater elasticity of substitution (transformation) within the group than between agriculture and non-agricultural aggregates. Visualized in terms of the flow chart, every agricultural box divides into the aggregate box and a set of arrows to 15 component boxes. Market clearance links the 15 home agricultural supply and demand boxes with heavy outside lines.

Second, government is absent from the flow chart. In the CGE model, the government collects taxes and distributes subsidies, with any net revenue redistributed to the representative private agent in a lump sum. These distortions occur on all traded goods margins and on domestic agricultural margins, so there are potentially a great many distortions (with endogenous revenues). Visualized in terms of the flow chart, all distorted transactions have arrows connecting to an aggregate net revenue box, which in turn has an arrow connecting to the national income box. (Government consumption is subsumed into that of the private agent in the CGE model and the flow chart alike so there is no separate accounting for it in either representation.) Third, government policy in the CGE model includes quotas, which means that the domestic prices of quota-constrained goods are determined simultaneously with other endogenous variables in the model, and the quota rent must be placed somewhere in the income-expenditure flow. The assumption made for 
this paper is that all the quota rent is either captured by rent-retaining quotas or lost entirely to foreigners. ${ }^{3}$ Visualized in terms of the flow chart, binding quotas set supply levels, appearing as a set of boxes on the left margin of the chart. Demand for quota constrained imports appears as a set of boxes on the right margin of the chart, with heavy outside linkage lines imposing market clearance. With quota rent being lost, there is no need to feed it back into national income.

The Appendix available on request from the author describes the model in more technical detail. One technical point of some general interest concerns computational tractability. Since the model is implemented with great detail on trade distortions, there are potentially hundreds of quotaconstrained goods with endogenous prices, which suggests a very large computational burden. As the Appendix shows, the highly structured substitution effects of the CES/CET model impose a recursive form which reduces the computational burden greatly.

\section{Results}

The analysis of agricultural price increases resulting from the Uruguay Round trade agreements depends on several important data estimates taken from other sources. The world price change of 15 agricultural commodities is taken from output of the RUNS model (Goldin and van der Mensbrugghe, 1995) in three scenarios. Subsection 1 describes the RUNS model and the estimates briefly. Agricultural price distortions are estimated by PSE and CSE calculations for these 15 commodities based on estimates done by the US Department of Agriculture. Subsection 2 describes the procedures briefly.

\footnotetext{
${ }^{3}$ It is also possible to have the rent captured by domestic rent-seekers who use up $100 \%$ of the rent in rent-seeking activity.
} 
Domestic agricultural production and trade data is taken from the FAO data base also used by Goldin and van der Mensbrugghe. Domestic distortions as represented by PSE and CSE data are taken from the USDA estimates.

Nonagricultural trade and trade distortion data is taken either from the TRAINS data set or from country economists at the World Bank and transformed into 4 digit HS code data suitable for further analysis. Data limitations here dictate the countries and years chosen for the study. In all cases, the years conform to the reference data period (1985-93) for which the RUNS model is fitted. In some cases there is apparently missing information. Bangladesh is treated as having no NTBs because no information was available on NTBs for Bangladesh in 1993. Subsection 3.3 describes the procedures briefly.

Because of the high dimensionality of the nature of describing the results of agricultural price changes in 15 commodities for 9 countries, the description to follow gives summary welfare results for all countries followed by detailed results for India. India is singled out because the distortion effect differs in sign from and dominates the terms of trade effect (it is one of three such cases), and a decomposition of the underlying structure of distortions gives some insight into why this happens. 


\subsection{Estimates of agricultural price increases}

The RUNS model results are used as the primary source for forecast price changes. Goldin and van der Mensbrugghe present several scenarios, from which we select one (their scenario III) as the base case. For this scenario, recent data on agricultural protection are used and combined with countries' Uruguay Round submissions on tariff reforms and an assumed reduction of input subsidies ( $36 \%$ in OECD countries and $24 \%$ on other countries). The input subsidy reductions were an unrealized goal of the Uruguay Round. Sensitivity analysis is undertaken with two other scenarios provided by Goldin and van der Mensbrugghe, one with smaller price changes (their Scenario II) and one with larger price changes (their scenario IV). Scenario II modifies scenario III by not assuming any reduction in input subsidies in the major supplying nations. Scenario IV modifies scenario III by using the expectation rather than the actual achievement of the Uruguay Round: tariff reductions of $36 \%$ in OECD countries and $24 \%$ in other countries. Where agricultural protection is negative, no change is assumed. Several other price change scenarios were also applied, with results which add nothing to those reported here.

The RUNS model is described in Goldin and van der Mensbrugghe. Basically it is a very simple computable general equilibrium model designed to deliver detailed agricultural price estimates for 15 commodities while aggregating the rest of the production and trade structure. It is based on a multicountry world which breaks out the main agricultural trading nations separately. For purposes of this study, the results are accepted as reasonable forecasts, with sensitivity analysis presumed to pick up the major uncertainties involved. In this regard, it is worth noting a small inconsistency: the RUNS model used for the terms of trade change estimates assumes that all 
countries' outputs of each agricultural product such as 'wheat' are perfect substitutes in demand, whereas the CES/CET model used here assumes they are imperfect, though close, substitutes.

\subsection{Estimates of agricultural price distortions}

The PSE and CSE data are based on estimates by USDA using the standard method. For the PSE, all input subsidies are multiplied by the usage for each crop and summed together with any direct payments tied to production, then divided by the value of production at producer prices prior to subsidy/tax margins. A similar method is used for CSE calculations on the consumer side. The standard USDA PSE and CSE calculations include imputations for border adjustment measures. Based in the imperfect substitutes model of this study, the USDA method is invalid, so the estimates are modified (using the USDA detailed estimates of components) to deduct the effect of the trade measures.

Where PSE and CSE data are not available, we set the PSE and CSE equal to zero. The missing data problem is important, since in some cases the level of the PSE or CSE is quite influential: the results move about depending on whether the PSE and CSE are set at their actual values or to zero. This problem affects to some degree 5 of the 9 countries. In addition, for Bangladesh, the PSE and CSE data are for 1987 while the trade and trade distortions data are for 1993.

For some RUNS model commodity classifications there are differing PSE elements which belong to the commodity group. The aggregation procedure is with production weights, while for CSEs the aggregation is with consumption weights.

Finally, the PSE and CSE data is not always matched exactly with the year for which the other data is found. 


\subsection{Trade and trade distortions data}

In approaching operationality with trade distortions, tariffs are fairly simple in principle, but even here the question of the applicable rate causes difficulties in practice. Quotas, in contrast, present much greater difficulty from the outset because quota premia are generally missing and direct comparison of domestic and international prices to construct implicit premia is also generally not possible. Anderson (1995) and Anderson and Neary $(1994,1996)$ have attacked this problem by identifying NTBs with binding quotas, using an assumed demand structure to infer domestic price, and assuming that all rent other than that retained by tariffs is lost to foreigners or to rent seeking activity which uses up domestic resources. The same method is applied here.

The trade and trade distortions data come principally from the TRAINS data base, but some has been supplied by country economists at the World Bank. The availability of this data and the PSE and CSE data has been the chief selection criterion for countries and years. It is desirable to operate with distortions at the finest level of detail possible, but at the 'primitive' level, trade flows, NTB data and tariff data are not one-to-one in their classification systems. The best procedure is to aggregate to the first level for which consistent classification is universal --- in practice this is the 4 digit HS code level.

In the initial aggregation procedure for trade data 6 or 7 digit HS code trade flow data, nontariff barrier (NTB) data and MFN tariff data are transformed into 4 digit HS data as follows. (i) If $75 \%$ or more of the components of a 4 digit code line are judged to have 'hard core' NTBs (the term is from UNCTAD usage and includes such characteristics as being under US antidumping investigation), then the line is judged to have a 
binding quota. If fewer than $75 \%$ of the components have a hard core NTB, then the line is judged to be unconstrained. (ii) Trade weighted average tariffs for each line are calculated from the components. (iii) The component imports are summed to form the 4 digit level of imports. This procedure is also applied to the RUNS agricultural commodities.

\subsection{Validating the CGE Model}

The trade and agricultural data of preceding sections are combined with GDP, aggregate exports and current account surplus data from the World Development Report. The trade data and the current account surplus data combine to imply a net trade in factor services. This completes the list of data needed to set up the model.

The CES/CET model is specified in dual form, so that 'calibration' of the usual sort is unnecessary. The logic of the model is tested by making sure that for the initial equilibrium, all endogenous prices are indeed computed at the benchmark value of unity. The elasticities of substitution and transformation are set so as to give plausible import demand and export supply elasticities. Sensitivity analysis indicates that these elasticities are not influential for the qualitative results. Common values of elasticities are used for all 9 countries in the results reported below, but of course there is great variation across countries in the share parameters of supply and demand, reflecting different economic conditions.

\subsection{Results of the analysis}

The results of the study are summarized as follows.

First, unsurprisingly, small external price changes applied to a small part of an economy result in small (proportionate to GDP) changes in welfare. Since the RUNS price changes are all under 10\% in the base case and since 
agriculture is less than $10 \%$ of the GDP of the economies studied, welfare impacts are guaranteed to be small. Even here, however, there is a bit of a surprise in how large some welfare changes are in relation to this expectation as well as in relation to the standard terms of trade effect measure. The results for Colombia and Pakistan stand out in this way.

The surprisingly large welfare impacts are explained by the distortion effects. While the terms of trade effect and the distortion effect are not additive for discrete changes, it eases intuition to treat them as such. Treating the two effects as additive, the distortion effect is worth over $1 \%$ of national income in Pakistan. Colombia's case is almost as dramatic, with the distortion effect amounting to $0.6 \%$ of national income, while India's distortion effect is worth about $0.5 \%$ of national income.

Second, trade distortions are an important contributor to the distortion effect, amounting to nearly $0.6 \%$ of national income for Colombia and $0.1 \%$ for India and Pakistan. This raises an important issue of sensitivity analysis, because the treatment of NTBs has often been very influential in the analysis of distorted economies. The effect of trade liberalization is to raise real income, which raises the domestic price of NTB constrained goods and increases the rent loss, offsetting the incipient welfare gain(Loo and Tower, 1990 and Clarete and Whalley, 1988). In contrast, in this study the results are insensitive to the treatment of NTBs. This is because of the intersection of two special features: (i) due to data limitations, in the initial situation, all rent is assumed to be retained by rent retaining tariffs; i.e., NTBs are not binding at the margin, and (ii) the terms of trade changes for countries which use many NTBs turn out to be welfare reducing, rendering a nonbinding NTB even further from binding. 
Third, domestic agricultural distortions make a big difference in some results. Here the paucity of the data is especially unfortunate, because there are only 3 comparable cases. The case of Pakistan shows that its small conventional terms of trade effect loss would due to the distortion effect of trade distortions turn into a small gain if all domestic distortions were removed, while Pakistan's actual very large PSE and CSE distortions convert the small gain to a large loss. India also has a rather large effect of PSE and CSE distortions, worth about $0.35 \%$ of national income, while the effect of removal of PSE and CSE distortions is worth about $0.11 \%$ of national income to Colombia.

Fourth, the standard terms of trade effect and the 'true' welfare measures are weakly associated at best. In 3 cases out of 9 there is a sign reversal, while the overall correlation between the two measures ranges from 0.56 to 0.64 , depending on the scenario.

Finally, low quality data on trade distortions and on other distortions is potentially extremely costly to useful analysis. The results demonstrate that the presence or absence of distortion information can lead to sign reversals.

Table 1 gives the base case external price changes for the 15 commodities along with the two alternative scenarios. Scenarios are taken from Goldin and van der Mensbrugghe (1995) and correspond to their scenarios II, III and IV. Some experiments not reported here also used FAO estimates for basic grains price changes. 
Table 1. World Price Changes in three scenarios (\%)

$\begin{array}{lccc}\text { commodity } & \text { low } & \text { price case } & \text { base case } \\ \text { wheat } & 3.80 \% & 6.30 \% & 10.30 \% \\ \text { rice } & -0.90 \% & 0.80 \% & 3.60 \% \\ \text { coarse grains } & 2.30 \% & 3.20 \% & 5.40 \% \\ \text { sugar } & 1.80 \% & 2.50 \% & 11.40 \% \\ \text { beef } & 0.60 \% & 1.40 \% & 6.00 \% \\ \text { other meats } & -0.60 \% & -0.10 \% & 2.30 \% \\ \text { coffee } & -1.50 \% & -1.40 \% & -0.70 \% \\ \text { cocoa } & -0.70 \% & -0.60 \% & 0.30 \% \\ \text { tea } & -1.40 \% & -1.20 \% & 0.90 \% \\ \text { oils } & -0.30 \% & 3.90 \% & 5.40 \% \\ \text { milk } & 1.20 \% & 2.30 \% & 12.10 \% \\ \text { other food } & -1.40 \% & -1.50 \% & -0.70 \% \\ \text { wool } & -0.90 \% & 0.50 \% & 1.20 \% \\ \text { cotton } & -1.20 \% & -0.30 \% & 1.10 \% \\ \text { other non food } & 0.80 \% & 0.90 \% & 2.90 \%\end{array}$

Table 2 presents the money metric utility change results of the base case analysis, flanked by the results of the conservative World Bank ${ }^{4}$ case and the high price change. The fourth column gives the standard terms of trade effect for the base case (calculated as the initial level of imports or exports times the percentage change in world price, summed and divided by GDP).

\footnotetext{
${ }^{4}$ Dubbed this because Will Martin said these are the preferred numbers around the Bank.
} 
Table 2. Terms of Trade Effects and Welfare

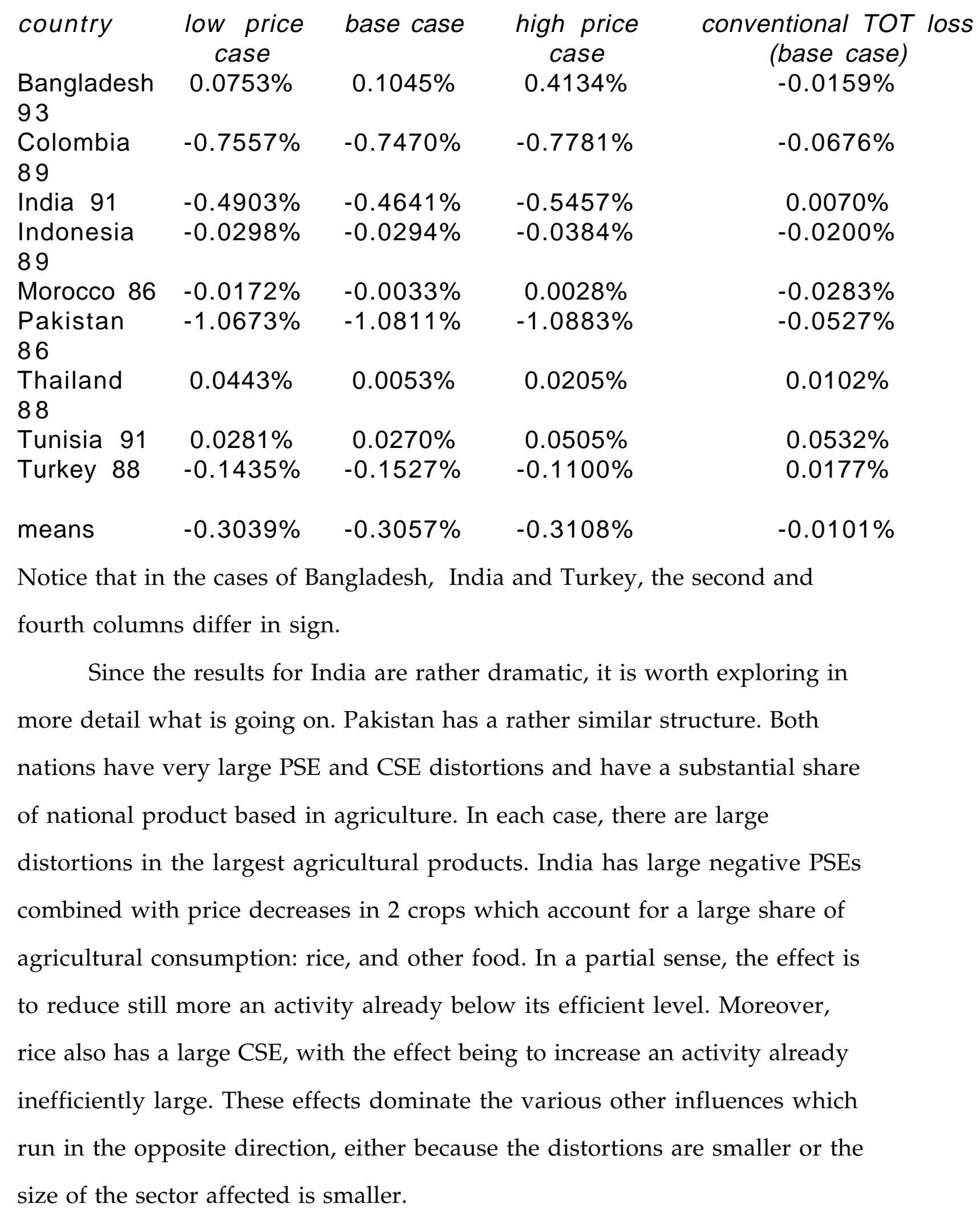


Table 3. The Structure of Supply, Demand and Distortion in India, 1991

$\begin{array}{lccccc}\text { commodity } & \begin{array}{c}\text { base case price } \\ \text { changes }\end{array} & \begin{array}{c}\text { export share } \\ \text { wheat }\end{array} & \begin{array}{c}\text { consumption } \\ \text { share }\end{array} & \text { PSE } & \text { CSE } \\ \text { rice } & 3.80 \% & 0.12 \% & 3.28 \% & -46.79 \% & 68.48 \% \\ \text { coarse } & -0.90 \% & 0.24 \% & 8.10 \% & -56.68 \% & 61.22 \% \\ \text { grains } & 2.30 \% & 0.00 \% & 2.22 \% & -53.77 \% & 47.66 \% \\ \text { sugar } & & & & & \\ \text { beef } & 1.80 \% & 0.01 \% & 1.36 \% & 0.00 \% & 0.00 \% \\ \text { other } & 0.60 \% & 0.14 \% & 6.18 \% & 0.00 \% & 0.00 \% \\ \text { meats } & -0.60 \% & 0.00 \% & 2.33 \% & 0.00 \% & 0.00 \% \\ \text { coffee } & -1.50 \% & 0.21 \% & & & \\ \text { cocoa } & -0.70 \% & 0.00 \% & 0.19 \% & 0.00 \% & 0.00 \% \\ \text { tea } & -1.40 \% & 0.39 \% & 1.20 \% & 0.00 \% & 0.00 \% \\ \text { oils } & -0.30 \% & 0.49 \% & 5.35 \% & 38.58 \% & -50.88 \% \\ \text { milk } & 1.20 \% & 0.00 \% & 17.11 \% & 0.00 \% & 0.00 \% \\ \text { other food } & -1.40 \% & 0.39 \% & 49.22 \% & -67.66 \% & -15.65 \% \\ \text { wool } & -0.90 \% & 0.00 \% & 0.06 \% & 0.00 \% & 0.00 \% \\ \text { cotton } & -1.20 \% & 0.34 \% & 0.69 \% & -51.02 \% & 83.22 \% \\ \text { other non } & 0.80 \% & 0.20 \% & 2.61 \% & 0.00 \% & 0.00 \%\end{array}$

food

The export share column gives the ratio of exports to total agricultural production for each commodity. The consumption share column gives the 'apparent consumption' (production plus imports minus exports) of each commodity to the total agricultural apparent consumption.

The effect of the removal of PSEs and CSEs for all (relevant) countries is detailed in Table 4. The analysis shows that PSEs and CSEs are quite influential. The first two columns give the percentage change in money metric utility under the zero PSE and CSE assumption and under the base case respectively. The case of Pakistan is striking in that with no domestic distortions its small terms of trade loss would be converted to a small welfare gain due to the trade distortions effect. The large domestic distortions effect arising from Pakistan's very large PSE and CSE values converts the gain to a loss of more than one per cent of national income. The case of Turkey likewise 
has the domestic distortions effect convert a small gain into a small loss. India is similar to Pakistan in that the presence of its also very substantial PSE and CSE distortions has a substantial domestic distortions effect worth over $1 / 2$ of one per cent of national income. In the other cases, the effect of assuming a zero initial PSE and CSE structure is less striking. Taken together, the results emphasize the sensitivity of results to the PSE and CSE data. An important task in future work will be to improve on the quality of distortion data.

Table 4. Sensitivity of Results to PSE and CSE measures zero PSE and Base Case state of distortions data CSE case

$\begin{array}{llll}\text { Bangladesh } & 0.1088 \% & 0.1045 \% & \text { rice and wheat only } \\ 93 & & & \\ \text { Colombia } & -0.6331 \% & -0.7470 \% & \\ 89 & & & \\ \begin{array}{l}\text { India 91 } 91 \\ \text { Indonesia }\end{array} & -0.1096 \% & -0.4641 \% & \\ 89 & & & \\ \begin{array}{l}\text { Morocco } 86 \\ \text { Pakistan }\end{array} & 0.0240 \% & -0.0294 \% & \text { PSE and CSE data, rice only } \\ 86 & & & \text { no PSE and CSE data } \\ \text { Thailand } & 0.0049 \% & 0.0053 \% & \text { PSE and CSE data, rice only } \\ 88 & & & \\ \text { Tunisia 91 } & & & \text { no PSE and CSE data } \\ \text { Turkey 88 } & 0.0251 \% & -0.1527 \% & \end{array}$

In contrast the results are generally not sensitive to the elasticity values, even in the case of Pakistan where it might be expected to matter most. This echoes a finding reported in Anderson (1995) and Anderson and Neary (1996), so it will not be reproduced here. ${ }^{5}$

Finally, the qualitative results are only slightly sensitive to the particular details of the assumed agricultural price changes. The first three

\footnotetext{
${ }^{5}$ When some import categories have zero imports, the elasticity values are restricted, for numerical methods reasons. In this case an elasticity of substitution less than one is inconsistent with zero imports, so it is necessary to bound the elasticity above one. The numerical methods problem is that it is necessary to avoid dividing by zero.
} 
columns of Table 2 demonstrate this. Only in the case of Morocco is there a sign change, and for that case all the movement is in a small interval about zero so it is not 'significant'. The quantitative results are in some cases sensitive to the price changes assumed, most notably in the case of Bangladesh.

\subsection{Conclusion}

The impact of world price changes on the welfare of individual countries is substantially affected by their structure of distortions. Theory has long argued this proposition, without much evidence that it is true. Might not a simple back of the envelope calculation ignoring the complications of the theory of distortions perform reasonably well?

This study shows that simple calculations are likely to go wrong, even so much as to get the sign wrong fairly often. Specifically, the Uruguay Round trade agreements' impact on world agricultural prices strikes the welfare of a group of fairly highly distorted economies in sometimes 'perverse' ways, due to the distortion effect.

The broader lesson is that there is no substitute for quality data on both domestic and trade distortions. The paper shows that errors in this data are likely to be influential to conclusions, and the default assumption setting missing distortions data to zero is especially likely to be misleading. NTB distortions data are especially important, along with the rent sharing assumptions as to the quota rents. In contrast, at least within the model structure imposed throughout, the importance of elasticities is slight; they do not much influence results. 


\section{References}

Alston, J. and W. Martin (1995), "A Comment on Border Price Adjustments and Domestic Welfare in the Presence of Distortions", Oxford Economic Papers, 47, 79-82.

Anderson, J.E., G. Bannister and J.P. Neary (1995), “Domestic Distortions and International Trade", International Economic Review, 36, 139-158.

Anderson, J.E. (1995), "Trade Restrictiveness Benchmarks", Boston College.

Anderson, J.E. and J.P. Neary (1996), “A New Approach to Evaluating Trade Policy", Review of Economic Studies, 64, 107-125.

Anderson, J.E. and J.P. Neary (1994), "Measuring the Restrictiveness of Trade Policy", World Bank Economic Review, $\underline{8}, 151-170$.

Anderson, K. And R. Tyers (1993), "More on Welfare Gains to Developing Countries from Liberalizing World Food Trade", Journal of Agricultural Economics, $\underline{44}(2), 189-204$.

Clarete, R.L. and J. Whalley (1988), "Interactions between Trade Policies and Domestic Policies in a Small Open Economy", Journal of International Economics, 24,

Goldin, I. and D. van der Mensbrugghe (1995), "The Uruguay Round: An Assessment of Economywide and Agricultural Reforms", in W. Martin and L.A. Winters, eds, The Uruguay Round and the Developing_Economies, Washington: World Bank.

Krueger, A.O., M. Schiff and A. Valdes (1988), "Measuring the Impact of Sector-specific and Economy-wide Policies on Agricultural Incentives in LDCs", World Bank Economic Review, 2, 255-72.

Loo, T and E. Tower (1990), "Agricultural Liberalization, Welfare, Revenue and Nutrition in Developing Countries" in I. Goldin and O. Knudsen eds. Agricultural Trade Liberalization, Paris: OECD.

Lopez, R. and A. Panagariya (1992), "On the Theory of Piecemeal Tariff Reform: The Case of Pure Imported Intermediate Inputs", American Economic Review, 82, 615-625.

Tyers, R. and R. Falvey (1989), "Border Price Changes and Domestic Welfare in the Presence of Subsidized Exports", Oxford Economic Papers, 41, 434-451. 


\section{Appendix: Technical Description of the CES/CET Model}

Not for publication.

For simplicity the first section takes up the trade distortions only case. The second section then adds the complication of domestic consumer and producer distortions. The third section deals with quotas.

\subsection{Trade Distortions Only Case}

The final demand structure is described by a 2 level CES expenditure function:

$$
\begin{aligned}
e(P A, h, \pi, u) & =\left(\alpha^{A} P A^{1-\sigma^{*}}+\Sigma \alpha_{j} \pi_{j}^{1-\sigma^{*}}+\Sigma \alpha_{k} p_{k}^{1-\sigma^{*}}+\alpha_{y} h^{1-\sigma^{*}}\right) \frac{1}{1-\sigma^{*}} u \\
& =P u,
\end{aligned}
$$

where $\mathrm{P}$ is the consumer price index, $\mathrm{PA}$ is the price index of agricultural goods, $h$ is the price of the nonagricultural nontraded good, $\pi_{j}$ is the typical element of a vector of final nonagricultural import prices not subject to quota, $\mathrm{p}_{\mathrm{k}}$ is the typical element of a vector of final nonagricultural import prices subject to quota, $\sigma^{*}$ is the elasticity of substitution and $u$ is the level of utility.

The price index of the agricultural composite is a CES function of the the prices of a set of nontraded agricultural goods $\left\{h_{A_{s}}\right\}$, the prices of a set of imports not subject to quota, $\left\{\pi_{A_{s}}\right\}$, and of a set of imports subject to quota, $\left\{p_{A_{s}}\right\}$.

$$
P^{A}=\left(\Sigma \beta_{s} p_{A s}^{1-\sigma_{A}}+\Sigma \gamma_{s} \pi_{A s}^{1-\sigma_{A}}+\Sigma \delta_{s} h_{A s}^{1-\sigma_{A}}\right)^{1 /\left(1-\sigma_{A}\right)} .
$$

The use of the subscript s here denotes that consumption of wheat, for example is composed of a domestic good and an imported good, the latter being either subject to quota or not subject to quota.

The level of domestic production activity is denoted $Z$. The activity is split into a composite agricultural production good, a nonagricultural 
nontraded good, and a nonagricultural export. The composite agricultural product is split into a vector of home agricultural outputs and a vector of agricultural exports. The activity is produced by a vector of imported inputs and a single nontraded primary product with CES technology. The highly aggregated production structure implicitly contains within it the usual structure of interindustry flows. Its substitution effects structure thus imposes strong implicit restrictions on the underlying disaggregated production structure. Note that imported agricultural goods are treated as final goods, rather than as imported inputs.

Parallel to the 2 level CES consumer price index $\mathrm{P}$ is a 2 level constant elasticity of transformation producer price index $\phi$. The value of the domestic activity is equal to $\phi \mathrm{Z}$ and the various conditional supply functions are equal to $Z$ times the derivatives of $\phi$ with respect to the output prices. This parallels the expenditure function and its properties, as expenditure is equal to $P u$ and $P_{\pi} u$ is equal to the vector of demand for final non-quotaconstrained imports, etc. The producer price index is:

$$
\phi=\left(s^{A} \phi^{A^{1+\theta}}+s^{H} h^{1+\theta}+{ }_{s} X \pi^{X^{1+\theta}}\right)^{1 /(1+\theta)},
$$

where $\theta$ is the elasticity of transformation, the superscript $A$ denotes agricultural production, $H$ denotes nontraded (home) good production and $X$ denotes nonagricultural export production. The agricultural producer price index $\phi^{A}$ is:

$$
\phi^{A}=\left(\Sigma s_{k}^{A H}\left(h_{k}^{A}\right)^{1+\theta_{A}}+\Sigma_{s_{k}}^{A X}\left(\pi_{k}^{A X}\right)^{1+\theta_{A}}\right)^{1 /\left(1+\theta_{A}\right)} .
$$

Here the superscript $A H$ denotes agricultural production for the home market and $A X$ denotes agricultural production for the export market.

The determination of the level of $Z$ and of the prices of quotaconstrained goods follows the treatment of Anderson (1995) so will not be repeated here. One difference must be detailed. The final price index for 
agricultural goods does not have a closed form solution. The implicit solution used is derived as follows. First, differentiate $P u$ with respect to $p_{j}^{A}$ to obtain the demand for agricultural import $j$ subject to quota. Second, set demand equal to the quota $q_{j}^{A}$, and solve for $p_{j}^{A}$. Third, substitute the resulting expression for $p_{j}^{A}$ into equation (2). Fourth, raise both sides to the power $1-\sigma_{A}$. The result is:

$$
\begin{aligned}
P^{A^{1-\sigma_{A}}}=\left(\sum_{j}\left(\beta_{j}\right)^{1 / \sigma_{A}}\left(q_{j}^{A}\right)^{1-1 / \sigma_{A}}\right)\left(\alpha^{A}\right)^{1 / \sigma_{A}-1} \mathrm{P}^{\sigma\left(1-\sigma_{A}\right) / \sigma_{A}} u^{\left(1-\sigma_{A}\right) / \sigma_{A}}\left(P^{A}\right)^{\left(1-\sigma_{A}\right)\left(\sigma_{A}-\sigma_{)}\right) / \sigma_{A}} \\
+\sum_{s} \gamma_{s} \pi_{A s}^{1-\sigma_{A}}+\sum_{s} \delta_{s} \mathrm{~h}_{A s}^{1-\sigma_{A}}
\end{aligned}
$$

The model requires that the home goods markets clear. Formally, the home agricultural goods markets must clear to determine the set of home goods prices $\left\{h_{A_{s}}\right\}$. Thus for each home agricultural good $k$ :

$$
\alpha^{A}\left(P^{A} / P\right) \quad{ }^{-\sigma} \delta_{k}\left(h_{A k} / P^{A}\right)^{-\sigma_{A}} \quad u=s^{A}\left(\phi^{A} / \phi\right){ }^{\theta} \quad s_{k}^{A H}\left(h_{A k} / \phi^{A}\right)^{\theta_{A}} \quad Z .
$$

Since there may be a large number of agricultural goods, the combined dimension of equations (5) and (6) represents a considerable computational burden. Fortunately, equation (6) can be solved for $h_{A_{k}}$ in terms of $\left\{\mathrm{P}, \mathrm{P}^{\mathrm{A}}, \phi, \phi^{\mathrm{A}}, \mathrm{u}, \mathrm{Z}\right\}:$

$$
h_{A_{k}}=\left(\frac{\delta_{k}}{s_{k} H} \omega\right)^{1 /\left(\theta_{A}+\sigma_{A}\right)}
$$

where the common factor $\omega$ contains the general equilibrium variables:

$$
\omega=\frac{\alpha^{A} u P \sigma(P A) \sigma_{A}-\sigma}{{ }^{A} Z \phi^{-\theta}\left(\phi^{A}\right) \theta_{A^{-} \theta}} .
$$

The results can be substituted for $\left\{h_{A_{k}}\right\}$ in all the various functions for computational purposes. This is the procedure used to solve the model.

The model is completed by the balance of trade requirement, modeled as before with the addition that agricultural imports are distorted, agricultural and nonagricultural exports are possibly distorted and each receive different treatment in terms of elasticity structure. Finally, it is 
possible to distinguish agricultural consumption, production, imports and exports separately and treat distortion margins on each.

\subsection{Domestic Distortions}

The problem of this section is that domestic consumption and production of agricultural products is distorted in addition to agricultural trade. Each agricultural sector $k$ has a producer subsidy $\rho_{k}$ and a consumer subsidy $\eta_{k}$. The consumption subsidy is assumed to apply to domestic goods only in sector $k$. The alternative is to apply the subsidy both to imported and domestic goods in sector $k$, which would double count subsidization if imports are subsidized, and which in any case seems likely to treat as identical products which in fact are not identical.

The preceding model must be modified in two essential ways. First, the variable $h_{A_{k}}$ now represents the 'market' price, with producers receiving $h(1+\rho)$ and consumers paying $h /(1+\eta)$. Equation (7) becomes

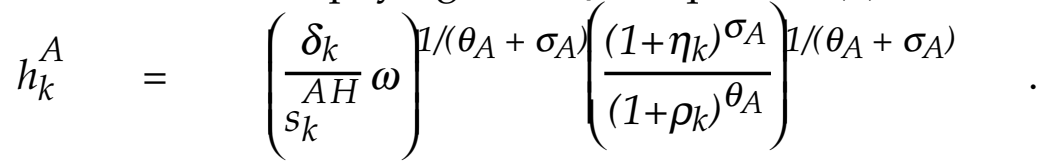

Second, the net subsidy payments become part of the government net revenue, hence enter the balance of payments function. The first step is to solve for the consumption/production of the kth home agricultural good:

$$
\phi_{\phi_{A}} \frac{\partial \phi_{A}}{\partial\left[h_{k}^{A}\left(1+\rho_{k}\right)\right]} \quad Z \quad=\quad s_{s}^{A}\left(\frac{\phi^{A}}{\phi}\right)^{\theta} \quad s_{k}^{A H}\left(\frac{h_{k}^{A}\left(1+\rho_{k}\right)}{\phi^{A}}\right) \theta_{A} \quad Z .
$$

The net subsidy payment is then

$$
S \quad=\quad Z_{s} A\left(\frac{\phi^{A}}{\phi}\right)_{k}^{\theta}\left(\eta_{k}+\rho_{k}\right) \quad h_{k}^{A} \quad s_{k}^{A H}\left(\frac{h_{k}^{A}\left(1+\rho_{k}\right)}{\phi^{A}}\right) \theta_{A} .
$$

\subsection{Cross effects with quotas}

A crucial feature of the CES/CET model is that binding quotas are assumed to give rise to rents which are lost to foreigners. A rise in the price of 
an agricultural export causes demand to shift toward quota constrained goods, increasing the rent lost to foreigners and thus creating an offset to the usual terms of trade effect.

Formally, using the methods of Anderson and Neary (1992), the marginal welfare effect of a rise in agricultural price a is

$$
-m_{a}+\left(\pi-\pi^{*}\right)^{\prime} E_{\pi \alpha}-\omega q^{\prime} p_{a \prime}
$$

where $m_{a}$ is the excess demand for the agricultural good a (so it is negative when a is exported), $\pi$ is the domestic price of unconstrained imports, $p$ is the domestic price of constrained imports, $\omega$ is the fraction of rent lost to foreigners and $\mathrm{q}$ is the quantity of constrained imports. For the case of substitutes, which holds for the CES/CET model, $E_{\pi a}>0$ and $\omega q^{\prime} p_{a}>0$. Summarizing the welfare effects, the first term (the usual terms of trade effect) is positive for exports and negative form imports of a, the second term (the tariff revenue effect) is positive for substitutes and the third term (the rent loss effect) is negative for substitutes. 